\title{
Стратегии смыслообразования: переход от дуальности к триалектике
}

\author{
Ирина В. Абакумова', Михаил В. Годунов² ${ }^{*}$ Денис В. Пеньков ${ }^{3}$ \\ ${ }^{1}$ Донской государственный технический университет, г. Ростов-на-Дону, Российская \\ Федерация \\ 2 Частное образовательное учреждение дополнительного профессионального обра- \\ зования «Школа Сотворчества», г. Ростов-на-Дону, Российская Федерация \\ ${ }^{3}$ Негосударственное образовательное частное учреждение дополнительного про- \\ фессионального образования «Краснодарский многопрофильный институт допол- \\ нительного образования», г. Краснодар, Российская Федерация \\ *E-mail: godunmv997@gmail.com
}

\begin{abstract}
Аннотация
Введение. Авторы преАлагают, исходя из проведенных ранее исследований смыс^ообразования на основе биполярных семантических шка^ ^ичностных свойств, переходить к триалектическому изучению стратегий смыслообразования. Такой взгляА обеспечивает провеАение мультифракторной Аиагностики ценностно-смысловой сореры для более качественного моделирования поведения человека в различных ситуациях взаимодействий.
\end{abstract}

Теоретическое обоснование. В соответствии с трехуровневой внутренне-целостной моделью ^ичности по А. А. Аеонтьеву, имеется некоторое взаимное соответствие межАу Аичностными смыслами и Аичностными свойствами, проявляемыми во взаимодействиях различного порядка. При рассмотрении телесности, чувственности, ментальности, каузальности и параАоксальности, как п^анов взаимолействия и развития мичности, авторами предлагается рассматривать смыслы как полимодальные каузальные образы поступков и отношений.

Результаты и их обсужАение. Смыслообразующая стратегия определяет направ^ение и качественное содержание генерируемого образа-смысла. Аля более алекватного моАелирования возможных стратегий, отражающих ключевые свойства мичности, авторы считают целесообразным переходить на следующий - триалектический уровень рассмотрения смысловой системы. В качестве оригинального поАхода преАлагается соответствующая триада: гипоаАаптивная, гиперадаптивная и преалаптивная смыслообразующие стратегии. Это позволяет направить фрокус исследовательского внимания на установление соотношений межАу Аанными смыслообразующими стратегиями как полюсами разнопланового развития ^ичности. Такие соотношения могут выявляться благодаря наличию некоторого взаимного соответствия межАу ценностно-смысловой сорерой и личностными свойствами, 
прояв^яемыми в различных Ситуационных взаимодействиях. ПреА^агаемый поАхоА позволяет выявлять ^ичностный профриль, выступающий мультифакторной моАелью возможных состояний ценностно-смысловой сфееры переживающего субъекта. В плане молелирования поведения выявляемый мичностный проффиль отражает не только направленность смысловой регуляции, но и качественное содержание генезиса ^ичностных смыслов - показывает актуальную стратегию образования смыслов, яв^яющихся полимоАальными каузальными образами отношений и поступков.

\section{КАючевые слова}

смысл, смысловая сорера, смыслообразование, стратегия смыслообразования, свойство ^ичности, полярная шкала, троичность, гипоаАаптивная стратегия, гипералаптивная стратегия, преалаптивная стратегия

\section{Основные положения}

- смыслы рассматриваются как полимодальные каузальные образы исходя из иерархии влияния на функционирование мичности;

- Аополнено понятие стратегии смыслообразования и прелложены определения троичных смыслообразующих стратегий: гипоадаптивной, гипералаптивной и преалаптивной;

- на основе взаимного соответствия смыслов и свойств ^ичности преАлагается использовать троичные шкалы ^ичностных свойств А^я описания смыслообразующих стратегий.

\section{Для цитирования}

Абакумова И. В., Годунов М. В., Пеньков Д. В. Стратегии смыслообразования: переход от дуальности к триалектике // Российский психологический журнал. 2019. Т. 16, № 1. C. 52-76. DOI: 10.21702/rpj.2019.1.3

Материалы статьи получены 02.08.2018

UDC 159.99

DOI: $10.21702 /$ rpj.2019.1.3

\section{Meaning-Building Strategies: Transition From Duality to Trialectics}

\section{Irina V. Abakumova', Mikhail V. Godunov2*, Denis V. Penkov}

${ }^{1}$ Don State Technical University, Rostov-on-Don, Russian Federation

${ }^{2}$ School of Co-Creation, Rostov-on-Don, Russian Federation

${ }^{3}$ Krasnodar Multidisciplinary Institute of Continuing Education, Krasnodar, Russian Federation

* Corresponding author. E-mail: godunmv997@gmail.com 


\begin{abstract}
Introduction. The authors suggest that instead of bipolar semantic scales of personal traits the focus of research on meaning-building should be shifted towards a trialectical framework of meaning-building strategies. This approach provides a multi-factor diagnosis of the value-meaning sphere of personality for better modeling of human behavior in various interaction situations.

Theoretical Basis. According to Leontiev's three-level internal integral model of personality, there are certain mutual correspondences between personal meanings and personal traits that manifest themselves in various interactions. In considering corporality, sensuality, mentality, causality, and paradoxicality as the areas for individuals' collaboration and development, meanings appear to be causal polymodal images of actions and relations.
\end{abstract}

Results and Discussion. Meaning-building strategy determines the orientation and content of the generated image-meaning. A trialectical framework for the consideration of the meaning system may help to provide more adequate modeling tools of possible strategies, which correspond to basic personal traits. The authors suggest an original approach which is based on the corresponding triad, namely hypoadaptave, hyperadaptive, and preadaptive meaning-building strategies. Thus, it is possible to establish correlations among these meaning-building strategies as poles of the multifaceted development of personality. Certain mutual correspondences between the value-meaning sphere and personal traits, which manifest themselves in various interaction situations, can help determine these correlations. The approach proposed by the authors is instrumental in revealing a personal profile as a multifactor model of possible states of the value-meaning sphere of the experiencing subject. In terms of behavior modeling, the revealed personal profile may not only determine the orientation of meaning regulation but also disclose the qualitative content of the genesis of personal meanings and demonstrates an actual strategy of building meanings as polymodal causal images of relations and actions.

\title{
Keywords
}

meaning, meaning sphere, meaning-building, meaning-building strategy, personality trait, polar scale, triplicity, hypoadaptave strategy, hyperadaptive strategy, preadaptive strategy

\section{Highlights}

- Based on the hierarchy of the influence on the functioning of personality, meanings can be considered as polymodal causal images.

- This study broadens the notion of meaning-building strategies and proposes a definition of triplicate meaning-building strategies - hypoadaptave, hyperadaptive, and preadaptive. 
Because of mutual correspondences between personal meanings and personal traits, triad scales of personal traits may be used to describe meaning-building strategies.

\section{For citation}

Abakumova I. V., Godunov M. V., Penkov D. V. Meaning-Building Strategies: Transition From Duality to Trialectics. Rossiiskii psikhologicheskii zhurnal - Russian Psychological Journal, 2019, V. 16, no. 1, pp. 52-76 (in Russian). DOI: 10.21702/rpj.2019.1.3

Original manuscript received 02.08.2018

\section{Введение}

При исследовании смысловой регуляции ранее нами рассматривалась элементарная персонологическая модель на основе дуальных соотношений личностных свойств [1]. Их представление в виде ансамбля биполярных семантических шкал показывало две стратегии организации смысловой сферы позитивное развитие или деградацию личности. Данный подход сводил все многообразие вариантов развития личности к парным противопоставлениям. Однако после такого логически простейшего дуального описания для более адекватного представления многомерной смысловой реальности требуется переходить на следующий методологический уровень.

В данной статье генезис свойств личности и обуславливающих их личностных смыслов рассматривается с триалектических позиций на основе троичности смыслообразующих стратегий. Такой методологический подход позволяет проводить мультифакторную диагностику и качественную интерпретацию различных состояний ценностно-смысловой сферы личности для моделирования ее поведения в различных жизненных ситуациях. Это помогает осознанию особенностей своего бытия и инобытия как условий духовного самосовершенствования в пути самотрансценденции.

Целью данной статьи являются теоретическое обоснование перехода от дуальной к триадной модели смыслообразующих стратегий и их описание.

\section{Теоретическое обоснование}

Следование холистическому взгляду на поведение человека предполагает при исследовании смысловой сферы изучение глубинных внутренних состояний (воспринимаемых значений происходящего как личностных смыслов) в совокупности с внешними проявлениями свойств его личности. Связи между внутренними смыслами и внешними свойствами личности составляют познавательный интерес в плане моделирования взаимного влияния ее структурных уровней для прогнозирования поведения в ситуациях взаимодействий. Согласно внутренне-целостной трехуровневой модели личности [2], имеется 
иерархическая система: мировоззренческое ядро, ценностно-смысловая сфера внутреннего мира и внешняя оболочка экспрессивно-инструментального уровня, отражающего характер, способности и роли взаимодействующего субъекта.

В рамках культурно-исторической концепции смысл первоначально рассматривался Л. С. Выготским как психолингвистическая категория. Она преобладает над значением высказывания, имея при этом доречевую природу, как аффективное отношение к внешнему миру [3]. Категория отношений в трудах В. Н. Мясищева рассматривается как результат отражения в сознании объективно существующего микро- и макробытия человека. При этом для формирования личностных свойств, составляющих нравственное ядро, в процессе деятельности необходимо организовывать отношения личности определенным образом: побуждать к сотрудничеству, взаимопомощи, коллективизму, подкреплять ход деятельности взаимоотношениями, побуждающими к нравственным поступкам [4]. Л. С. Выготским намечена позиция об обусловленности смысла мотивом деятельности, что впоследствии подробно рассмотрено А. Н. Леонтьевым [5]. Он доказал, что отношение мотива генерирует смысл, который, будучи пропущенным через такое отношение личности к происходящему, становится при этом личностным смыслом. Поэтому личностные смыслы имеют не только интеллектуальное содержание, но и глубокую эмоциональную окраску, как переживание.

По мнению В. М. Аллахвердова, приписывание смысла происходит в результате работы механизмов сознания, которые могут быть как осознаваемыми, так и неосознаваемыми. Такая работа заключается в том, что любой стимул или текст имеет не одно значение, при этом часть значений может восприниматься и при этом не осознаваться. Другая часть значений может осознаваться при условии непротиворечивого логического соединения с другими принятыми сознанием значениями. Приписанный сознанием смысл является одновременно и позитивным и негативным выбором, который имеет тенденцию к последействию [6]. Дальнейшая поступающая семантическая информация обрабатывается сознанием с учетом ранее сохраненных личностных смыслов как механизмов выделения и выбора.

А. В. Карпов считает, что изучение проблематики сознания является фундаментальной задачей общенаучного значения, и предлагает ее исследование с позиций метасистемного подхода. Его суть состоит в необходимости учета и привлечения в гносеологический арсенал методологического положения о том, что сознание относится к особому классу систем. В качестве кардинального отличия такой неклассической системы выступает локализация метасистемы [7]. Система сознания не только взаимодействует с внеположной объективной реальностью посредством психики как метасистемы, но и в своем собственно внутреннем содержании отражает метасистему. 
Таким образом, внешняя локализация метасистемы является не единственно возможной, а имеет место внутренняя локализация системы сознания, что становится очевидным на примере психики. Получаемое «удвоение бытия» в силу отражательного атрибута психики означает существование в сознании субъективной реальности - внутренней. Таким образом, сознание, как система со встроенным метасистемным уровнем психики, самопрезентируется, формируя «бытие-для-себя», а точнее «психику-для-себя», что представляется единственно возможной формой субъективного существования психики. Данное встраивание в систему сознания метасистемы психики означает, что последняя фактически прекращает свое субъективное существование и трансформируется в бессознательное. Такое субъективное бессознательное самим индивидом не может ощущаться по определению, хотя психика объективно формирует такой функционально необходимый механизм конституирования системы сознания [7]. Для него порождаемое бессознательное обладает противоположно качественным определением, следовательно, посредством такого механизма порождения бессознательного вносится неопределенность в работу сознания. Тогда стратегией поведения индивида для достижения наилучшей адаптации в окружающем мире исследователь предлагает обеспечивать более полное и адекватное совпадение внутренней и внешней реальности в сознании. Это означает требование максимального подобия объективной реальности по отношению к содержательным и информационным характеристикам психики [7].

При рассмотрении когнитивных механизмов работы сознания, по данным А. Ю. Агафонова, человеком в данный момент времени может осознаваться только та часть информации, которую он понимает. При этом в своей памяти он хранит намного больше информации, чем он способен узнать или вспомнить. При восприятии многозначных и неопределенных стимулов осознание возможно лишь в условиях выбора из образцов понимания внешних воздействий, которые уже наличествуют, присутствуют в сознании, но не осознаются [8]. Эмпирическое исследование эффектов прайминга (действия предшествующего подобного стимула) показывает, что осознание возникает как завершающий результат неосознаваемых поисковых процессов по интерпретации внешних воздействий. На выбор при принятии решения оказывает действие сила влияния как ранее осознанной, так и неосознанной информации. Также на осознание существенно влияет актуальная иррелевантная информация, даже если она не осознается. Поэтому процесс осознания является неизбежным следствием конкурирующего выбора среди неосознаваемых ходов понимания [8]. Тогда сознание рассматривается как множественное понимание, означающее приписывание нескольких смыслов для каждого явления действительности. 
С позиций экспериментальной психосемантики, по данным В. Ф. Петренко, в сознании переживающего субъекта содержится неповторимое семантическое пространство. В нем, как в уникальном «звездном небе», содержатся личностные смыслы как отражение отношений человека к единичным объектам [9]. Такая смысловая неповторимость является системой ориентиров для встраивания в сознание других людей, т. к. понимание человека возможно посредством переживания и прочувствования смоделированной системы смысловых конструктов. С такой понимающей позиции открывается взгляд на становление личности через «веер возможностей» [9, с. 98], в силу того, что человек обладает загадочной способностью - свободой воли.

При изучении смыслообразования интерес представляет не только генезис смыслового плана, поскольку личность - не есть законченный продукт, а скорее процесс [10], но и содержательное описание личности. Такое описание помогает проявить «веер возможностей» как набор путей развития личности посредством выявления актуальных личностных свойств. Такое описание на языке свойств (черт) означает системный взгляд на проблематику личности, поскольку смысловой подход, показывающий динамику изменения личности, необходимо дополнять определением ее актуальных свойств, отражающих состояние как комплексный психологический портрет. Например, Р. Кэттелл «предположил, что каждое слово, обозначающее то или иное свойство человека, потенциально представляет собой черту личности» [цит. по: 11, с. 569].

Поскольку характер, согласно трехуровневой структуре личности по Д. А. Леонтьеву, является частью личности и входит в оболочку внешнего экспрессивно-инструментального уровня [2], то понятие «свойство личности» шире понятия «черта характера». Известно, что свойство личности - отличительный признак, элемент личности, выражающий суть внешних и внутренних взаимодействий [1]. Исходя из этого, в рассматриваемой модели личности ее внешняя оболочка содержит свойства личности, проявляемые человеком в различных взаимодействиях. Будем рассматривать отношения, возникающие между смыслами и свойствами личности, как взаимно обусловленные и обладающие некоторым взаимным соответствием [1]. С одной стороны, это означает, что личностные свойства отражают только те смыслы, которые присутствуют в ценностно-смысловой сфере и мировоззренческом ядре данной личности. С другой стороны, под воздействием личностных смыслов формируются особенности взаимодействий и оценок-отношений в различных ситуациях, что выражается соответствующими личностными свойствами как отличительными признаками. Такая особенность находит выражение в том, что термин «смыслообразование» на английский язык более корректно переводить как «meaning-building» вместо формального 
перевода «sense-formation», с чем авторы сталкивались при переводе своих работ и изучении современных зарубежных источников.

В процессе своей жизни человек осуществляет различные взаимодействия как внутреннего, так и внешнего порядка с различной степенью согласованности [12]. Рассмотрим многомерность возникающих отношений и деятельности более подробно с позиций иерархии влияния на функционирование личности. В качестве планов развития и взаимодействия личности рассмотрим: телесность, чувственность, ментальность, каузальность, парадоксальность.

План телесности, как одна из интегральных характеристик экзистенциального опыта человека, с одной стороны, является фундаментом его психики, что подробно рассматривается в психоанализе. С другой стороны, в истории философских исследований дуализма тела и души показывается, что тело одухотворено, а душа телесна. Поэтому в настоящее время телесность, прежде всего, рассматривается с позиций биологического и социального, родового и универсального бытия, где жизнь выступает основополагающей человеческой ценностью. Телесность понимается не как сумма органов тела, а является в некоторой степени культивированным телом, приобретающим в дополнение к своим естественным характеристикам такие качества, которые формируются исторически для адаптации человека сначала в природной, а потом в социокультурной среде [13]. Телесность является предметом исследования для психологии экспрессивного поведения и телесно-ориентированных дисциплин психологии.

В плане чувственности содержится способность человека переживать аффективные состояния - эмоции (удовольствие, страдание, гнев и т. п.). В контексте гносеологии это отражает способность к «чувственному познанию» - восприятие посредством органов чувств. В кантовской философии указывается, что чувственность является способностью пассивного созерцания вследствие внешних воздействий, в отличие от интеллектуального созерцания. Чувственное представление, в отличие от рассудочного, показывает единичный предмет и дает непосредственное знание о нем. При этом априорными считаются только две формы чувственности - время, как форма внутреннего чувства, и пространство, как форма внешнего чувства [14]. Современные представления о чувственности как о восприятии окружающего и небезразличном к нему отношении рассматривают это только как предпосылку субъективного оценочного отношения. Однако это отношение-оценка становится возможным благодаря существованию некоторых объективных образцов и норм, задаваемых рассудком. Такие нормы вырабатываются в процессе предметно-практической деятельности человечества в истории и закрепляются в культурный идеал как единство познавательного, этического и эстетического [5]. 
План ментальности (лат. «тепs»- ум, мышление) содержит совокупность сознательных и бессознательных установок и предрасположенностей индивидов, а также социальных групп к определенному типу ценностей, мышления и действия. Менталитет человека, как образ мышления, представляет собой устойчивые психокультурные характеристики его сознания, которым относятся поведение, психологические реакции и приспосабливаемость к окружающей среде. Менталитет подразумевает также сопричастность человека к прошлому - как личному, родовому, так и историческому [15]. Ментальные схемы составляют план грубой информации, управляющей планом чувств. Именно на ментальном уровне содержатся семантические поля как поля значений для обозначения происходящего. В качестве управляющего сигнала ментальные программы могут обеспечивать наступление семантического биорезонанса явления усиления информационного воздействия на биологический объект в тех случаях, когда это информационное воздействие является семантически подобным внутренней семантической природе объекта [16].

В плане каузальности (нем. «саuse» - причина) происходит формирование упорядоченной (с разной степенью) картины мира в сознании человека, который выделяет источники и результаты происходящего. Это преследует главную цель - построение на основе имеющихся телесных, чувственных и ментальных данных по возможности непротиворечивой и целостной системы отображения реальности. Это установление, исходя из необходимости действующих закономерностей, таких, как детерминизм (лат. «determino»определяю), происходит в соответствии с универсальным законом причины и следствия. Категория причинности напрямую связана с пониманием механизмов строения мира и его познания. Именно на основе причинного воздействия по цепям причинно-следственных связей осуществляются создание, передача, хранение, обработка и использование информации в биологических и искусственных системах [16].

В классической рациональности имеет место «лапласовский детерминизм» как крайне упрощенное проявление детерминизма, которому присущи: монокаузальность как обусловленность только одной причиной; отсутствие случайностей, являющихся причинами непознанного порядка; понимание свободы как познанной необходимости. Для постнеклассического выхода из созданного замкнутого круга, порождающего крайний фатализм, следует признать наличие нелинейных синергетических систем: чувствительных к начальным условиям, обладающих мультистабильностью и имеющих точки бифуркации [13].

Если ментальный план содержит значение как информацию, то на каузальном плане происходит формирование в сознании смыслов как причинных образов - полимодальных образов мировосприятия. Это возможно в силу умения человека совмещать в процессе познания сразу несколько 
способов (модусов) освоения мира [17]. В древнеиндийской теории познания Санкхья говорится, что при встрече пяти чувств с объектом в акте восприятия рождается образ объекта [18]. Именно смыслы, как полимодальные каузальные образы, управляют ментальным планом и выступают источниками синергетического эффекта - запускают творческие акты и детерминируют деятельность индивида в целом [19].

В плане парадоксальности на основе понятых причинно-следственных связей возможна работа с ними как с осознанными образами для их преобразования. Парадокс (греч. «раradoxos» - неожиданный, странный) содержит иррациональное знание и не полностью подчиняется законам формальной логики. Парадоксальная логика, как способность в очевидном увидеть неочевидное (за деревьями разглядеть лес), вырабатывает нелинейные суждения, в которых нет полярных оценок, что позволяет нестандартно выйти за рамки противоположностей, а точнее, подняться к принципам организации системы и выбраться из смысловых тупиков. Такое духовное прозрение позволяет подняться выше рациональной логики; найти утверждение, не имеющее антитезиса; дает видение сквозь обусловленное. При данном подходе человек переходит из режима детерминированности (полной обусловленности) жизни к самодетерминации своей жизни, тогда и «обнаруживается парадоксальная вещь: в любой ситуации нет такого выбора, который мы не могли бы сделать» $[20$, с. 6]. Это план возможных состояний решений, с помощью которых идет управление каузальным планом как уровнем необходимого функционирования. Трансформация причин возможна только с более высокого уровня, поэтому план парадокса и является тем минимальным уровнем, с которого возможна работа с причинами. Развивать парадоксальное мышление помогают юмор, дзен-философия, умение пользоваться интуицией и тонко-чувственным (образным) восприятием.

\section{Результаты и их обсуждение}

В ходе исследования влияния смыслов на организацию и качественное содержание деятельности возникают вопросы определения способов организации ценностно-смысловой сферы и механизмов ее трансформации при переходе в новые условия или выборе других целей. Тогда динамика процессов образования смыслов будет показывать суть процессов, реализующихся во внутреннем и внешнем мире человека, что поможет более качественно предсказывать его поведение. Современный деятельностно-смысловой подход рассматривает образование смыслов как процесс их перетекания, распространения из ведущих структур ядра смысловой сферы к ее периферии - к частным проявлениям в конкретных жизненных ситуациях через проявление личностных свойств [19]. Это означает возможность не только 
активизации источников ситуативных смыслов, как каузальных образов поступков, но и регуляцию в целом деятельности индивида на основе собственного образа мира.

Стратегия образования смыслов отражает взгляд в настоящее из будущего, направленный на порождение новых причин как целевое программирование ситуаций для их смены и преодоления сопротивления среды. В отличие от тактики, работающей с необходимыми следствиями, стратегия содержит нелинейные переходы на основе парадоксальной логики возможного к новым уровням сложности функционирования. Стратегия занимается качественным переходом системы от одних тенденций (контекстов) к другим с помощью целеполагания из надсистемы. Стратегия, как фильтр от случайностей, позволяет генерировать из хаоса четкий список поступков для удержания задаваемого образа мира [21].

Смыслообразующая стратегия задает ход и знак генерируемого образа-смысла. В процессе становления личности происходит развитие стратегий образования смыслов, на основе которых актуализируется стратегия формирования жизненных смыслов. Смыслы, как полимодальные каузальные образы, составляют ядро ценностно-смысловой и мотивационной сфер личности, детерминирующих ее деятельность на всех уровнях бытия, что было показано выше. Тогда можно дать следующее определение: стратегия смыслообразования - это организованный под влиянием мотивов, потребностей, целей, опыта, субъективных отношений способ формирования и развития системы личностных смыслов для их содержательного и качественного наполнения, а также отражающий специфику и динамику осуществления индивидом актуализации смыслов в конкретных ситуациях жизнедеятельности [1].

Проведенное нами ранее моделирование на основе биполярных семантических шкал представляется начальным и наиболее упрощенным описанием личности на основе ансамбля ее свойств. Такая элементарная персонологическая модель строилась на основе дуальных соотношений личностных свойств, показывающих две стратегии организации смысловой сферы - позитивное развитие или деградацию личности [1]. Данный подход сводил все многообразие вариантов развития личности к противопоставлениям - как в черно-белом кино. В качестве начального шага для развития ансамблевого подхода при моделировании смысловой регуляции это было оправдано - для вскрытия ее механизмов и особенностей нужно было начать хоть как-то двигаться. Однако после такого логически простейшего дуального описания для более адекватного представления многомерной смысловой реальности требуется переходить на следующий методологический уровень. Поэтому бинарная логика описания стратегий смыслообразования может быть дополнена триалектической интерпретацией. Это помогает выявить 
большее количество смысловых нюансов и их специфические особенности, проявляющиеся в виде устойчивой стратегии, показать их разнородность и в то же время сопряженность, сходность в логике поведенческих проявлений.

В качестве художественного примера, живо иллюстрирующего вариативность смыслообразующих стратегий, показательна галерея типажей братьев Карамазовых. На их основе Ф. М. Достоевским описаны основные тенденции развития русского общества из общего корня - загнивающего барства (в образе их отца). Дмитрий - вспыльчивый, мятежный, легкомысленный, импульсивный, сластолюбивый; Алексей - религиозный правдоискатель, охваченный альтруистическими побуждениями; Иван - богоборец, рациональный и прямолинейный циник, отрицающий побудительную силу морали и не верящий в возможность высшего духовного творчества; Смердяков - ограниченный, малообразованный, жестокий и злой маргинал [22].

При социологическом изучении современного российского общества В. Е. Семенов предлагает типологию российских базовых менталитетов. На основе категоризации по оппозициям "дух - материя» и «коллектив - индивидуальность» выделяются ценностно-смысловые типы современного российского общества: религиозный менталитет - у образованных и энергичных, искренне верящих и придерживающихся традиционных духовно-нравственных ценностей, исповедуемых основными конфессиями; коллективистскосоциалистический (просоциальный) менталитет у людей, исповедующих социальную справедливость, коллективизм и общественно-полезный труд; индивидуалистско-капиталистический менталитет - либералы новой формации, стремящиеся к карьерному успеху, выбирающие материальное благополучие, без активной общественной позиции, с поклонением западной массовой культуре; криминально-клановый менталитет - участники «теневых» криминальных групп с соответствующим ценностно-мотивационным и культурным уклоном в сторону коррумпированности и «уголовной романтики»; представители эклектично-мозаичного псевдоменталитета с конформистскими умонастроениями - современные обыватели без устойчивого мировоззрения, с изменчивым менталитетом (собравшим осколки вышеуказанных типов), порожденным современной массовой медиакультурой и Интернетом [23].

Исходя из вышеизложенного, для более полного моделирования многообразия возможных стратегий целесообразно переходить на следующий триалектический уровень рассмотрения смысловой системы. В философии имеются редкие примеры использования троичных систем различной природы для описания человека. В Аристотелевой этике описывается три вида наклонностей души: порок в силу избытка, порок в силу недостатка, добродетель в силу обладания серединой [24]. В этом подходе все три наклонности считаются противоположными друг другу: находящиеся посредине добродетели 
души обладают избытком какого-либо качества сравнительно с пороком его недостатка и недостатком сравнительно с пороком избытка. Такая система фактически имеет расположение трех полюсов на одной линии, где середину занимает добродетель как уравновешенное, нейтральное состояние между двумя крайними полюсами. Согласно учению Платона, у Индивидуальной Души имеются три способности: волевая, аффективная и умственная - с приматом последней из них. Тогда в этике это отражает три добродетели в виде мужества, просветленного состояния аффектов и мудрости, которые объединены одной цельной добродетелью, выражающей их равновесие - справедливостью [25].

В более поздней философской традиции известны случаи использования триады для обозначения тройственного ритма движения бытия и мышления, например, в неоплатонизме и немецком классическом идеализме. В неоплатонизме, в частности у Прокла, разработан триадический метод для описания трех стадий (ступеней) в движении бытия: пребывания в себе как в единстве, выступления из себя (эманации) из-за различения с ним, возвращения из инобытия обратно к себе [26]. У Гегеля триада лежит в основе построений философской системы о прохождении процессуальности через три стадии: тезис, антитезис и синтез, снимающий их противоречие, уничтожающий форму и изменяющий содержание процесса, при этом сохраняющий его жизнеспособные элементы в переходе на более высокую стадию развития [27].

Следует обратить внимание, что два последних подхода отражают взгляд на процессуальность происходящего как последовательность стадий бытия, однако в данной работе фокус внимания направлен на установление соотношения между различными полюсами как стратегиями смыслообразования в структуре системы личности, что может быть отражено через проявление ее свойств.

В психологии для изучения личности известен триадический метод репертуарных решеток на основе личностных конструктов Дж. Келли [28]. Этот метод в социально-психологической модификации М. Ю. Кондратьева позволяет по особенностям выявления сходства между двумя объектами и их отличия от третьего выстраивать шкалу субъективных оценок и личных предрасположенностей в различных ситуациях. В исследовании, проведенном под руководством Д. А. Леонтьева, выявлено наличие трех видов личностного выбора: 1) реактивный выбор - на основе непосредственных предпочтений при отсутствие внутренней проблематизации и развернутой внутренней деятельности, т. е. лишенный осмысленности под действием случайностей; 2) активный выбор неизменности - человек использует имеющиеся у себя компетенции, задатки, интересы для продолжения пребывания в зоне комфорта с отказом от новых возможностей; 3) активный выбор неизвестности - при ориентации на новые возможности и понимание своего опыта как требующего 
новых способов действий, т. е. предпочтение риска с неясными альтернативами [29]. При моделировании многоуровневой педагогической реальности А. А. Остапенко предлагает вводить третий полюс в различные обучающие дискурсы для снятия оппозиции «Я - Мы». Например, для традиционной диады: индивидуализм (гуманистическое Я над Мы) против коллективизма (советское Мы над Я) предлагается на основе православного мировоззрения применять иерархию, когда старший отвечает за младшего (христианское Я в Мы) [30].

Нами предлагается триалектический подход в изучении семантической организации ансамбля свойств личности. К такому троичному подходу подтолкнуло следующее обстоятельство, выявленное в биполярных семантических шкалах [1]: иногда в шкале рядом оказывались негативные личностные свойства, хотя и близкие семантически, но имеющее при этом разную степень выраженности, наполнения по типу «недостаток - избыток». Переплетенные свойства можно «расплести» - из смысловой «косички» одного полюса могут получаться две «растяжки», ветви. Тогда в биполярной шкале проявляется третий полюс, который становится центром третьей смыслообразующей стратегии в данном конструкте. Наличие таких логически необходимых отношений обусловлено различной мерой проявления противоположных смысловых начал, отражающей их количественно-качественное соотношение.

Первая, гипоадаnтивная (гр. «һуро»- внизу, снизу, под) смыслообразующая стратегия показывает отсутствие или недостаточное проявление ключевого свойства личности в данном смысловом диполе. Это отражает слабые адаптационные способности при взаимодействиях в ситуации, проявляемые как пассивное приспособление по типу реактивного выбора для сохранения имеющихся предпочтений. Это проявляется в виде отсутствия или фрагментарности осмысленного подхода в деятельности и принятии решений. Такая реактивная позиция отражает недостаточную работу во внутреннем мире для адекватной оценки происходящего и полноценного встраивания в процессы внешнего мира. Главный атрибут этой стратегии - недоразвитость, для преодоления которой китайская Книга Перемен предлагает прохождение ученичества. Просвещение, как общение с Учителем, необходимо для раскрытия заложенных в ученике способностей, ибо его уход в самого себя останавливает внутреннюю жизнь [31]. Однако нахождение недоразвитого в состоянии ученичества закономерно до определенного уровня, только до некоторого времени, после которого недоразвитость становится уже незакономерной. Эта задержка в развитии проявляет порок недостатка инфантильность в виде сохранения и доминирования набора личностных свойств, присущих более ранним ступеням развития.

В основном такая детскость, как «застревание» на более ранних этапах становления личности, проявляется в неумении или нежелании своевременно 
принимать продуманные решения. Инфантильный человек сконцентрирован только на себе, при этом как личность он не развивается, и самоанализ ему чужд. Такие люди часто не понимают окружающих, не разделяют их взгляды на мир и в поведении практически не считаются с их интересами. Основные признаки психологического инфантилизма: несамостоятельность и избегание проблем; отсутствие жизненных целей и стремлений; нежелание развиваться; неадекватные реакции на происходящее; эгоизм и безответственность; чрезмерная увлеченность играми, гаджетами, шопингом; неумение общаться; поверхностное мышление; малоподвижный образ жизни [32]. Такие особенности мировоззрения формируют соответствующие личностные смыслы, которые, как каузальные образы, детерминируют жизнь человека. У «взрослого ребенка» незрелость часто проявляется неспособностью или нежеланием брать на себя ответственность за свою жизнь - экстернальностью. Это означает ориентацию на внешний локус контроля своей жизни, когда ее значимые события и результаты деятельности слабо зависят от собственной активности. Человек с таким низким уровнем субъективного контроля убежден, что его успехи и неудачи - результат воздействия исключительно внешних сил: везения, случайностей, давления окружения, других людей [33].

При гипоадаптивной стратегии еще одним деформированным конструктом Я-концепции является виктимность (лат. «victima»- жертва) как склонность становиться жертвой внешних обстоятельств. Такая особенность межличностного поведения, как «синдром жертвы», связана с неадекватно заниженной самооценкой, с чувством обделенности, с неспособностью или нежеланием отстаивать собственную позицию. Это может приводить к тому, что «человек-жертва» ненамеренно навлекает на себя агрессию со стороны других людей и провоцирует преступление [34]. В смысловом диполе «жертва - воин» проявление виктимности соответствует полюсу пассивной позиции человека, терпящего все внешние воздействия. В стрессовых ситуациях данная стратегия направлена на то, чтобы прятаться от решения и избегать действий.

Нами предлагается следующее определение: гипоадаптивная смыслообразующая стратегия - это опирающийся на формальные предпочтения способ формирования каузальных образов, направленный на пассивное присоединение и ведомое движение в слое личностных смыслов, задаваемых непреодолимыми обстоятельствами жизнедеятельности без их фактического осознания.

Вторая, гиперадаптивная (греч. «hурег»- сверх нормы, чрезмерно) смыслообразующая стратегия показывает избыток ключевого личностного свойства, является ассимиляционной и направлена на активное приспособление человека. В таком типе приспособления выражается стремление индивида игнорировать приходящие в его жизнь неизбежные перемены и оставаться 
в зоне комфорта. Для сохранения такого состояния неизменности человек задействует все доступные ресурсы. Ключевой характеристикой личности в этой стратегии выступает переразвитие. Книга Перемен описывает это как порок избытка в виде образа старости, которая всего достигла и с гордостью ждет только покоя. Такое удовлетворение заработано всем, что было сделано на предыдущих ступенях, но это удовлетворение замкнуто само в себе и означает замыкание человека в своей личной жизни без внимания к окружающим. Опираясь на покой, нельзя построить благополучие - необходимы скорейший выход из застоявшейся ситуации и ломка старого [31].

Полюс гиперадаптивности отражает трансгрессию личности. Это процесс излишней персонализации, когда человек примеряет на себя чужие роли, маски, которые считает для себя приемлемыми. Идет зацикливание на собственном еgо, главным критерием становится соизмерение с другими и личный интерес, но не общепринятая норма, которая как раз и преступается. Такое самопозиционирование и стремление казаться, а не быть личностью видится как десакрализация реальности и десоциализация человека как разобучение [35]. Переразвитие, перенапряжение и пресыщение при гиперадаптивности, как форма социального опыта, может проявляться в сверхконтроле как своих, так и чужих взаимодействий. Ментальный «охват» ситуаций и излишняя гиперопека приводят не только к навязыванию чужой воли ее участникам, но и нарушают свободу их действий, ограничивая развитие и личности и группы. Состояние переразвития, как гипертрофированности, часто приводит к излишнему набору материальных благ и внешних атрибутов успешности. В смысловом диполе «жертва - воин» личность в состоянии переразвития может занимать активную воинствующую позицию. В этой крайней позиции состояние «воина» - это внутренняя характеристика человека, настроенного на постоянное противоборство с кем- или чем-либо; при этом он может проявлять неоправданную жесткость и даже жестокость.

В ситуации фрустрации, когда при столкновении с препятствием не получается добиться своих целей или удовлетворить потребность, у гиперадаптивной личности часто проявляются раздражение, агрессия. При этом высказываются негативные эмоции по поводу возникшей ситуации, ее причин. Окружающие люди осуждаются, поучаются, высмеиваются, либо побуждаются к действиям, при этом только от них и ожидается решение проблем. В теории Розенцвейга о фрустрационной толерантности это показывает экстрапунитивную направленность реакций, отражающую в нестандартной ситуации препятственно-доминантный тип взаимодействий как деструктивный [36].

Наличие гиперадаптивной стратегии показывает нежелание расширять свой опыт, а человеку в постоянно меняющемся мире необходимо при своем развитии проходить искушение переразвитием и избавляться 
от соответствующих иллюзий. Отсутствие такой внутренней работы ведет к формированию соответственных негативных каузальных образов, перекрывающих направление личностного роста и задающих горизонтальное движение - однообразное развитие в самоподобных формах.

Нами сформулировано следующее определение: гиперадаптивная смыслообразующая стратегия - это основанный на собственном опыте и стереотипной предзаданности достигнутых целей способ формирования каузальных образов, направленный на сохранение неизменного содержания личностных смыслов с применением для этого всех доступных ресурсов и отказом от новых возможностей развития смысловой сферы.

Между этими двумя адаптивными стратегиями находится нейтральное состояние, отражающее одинаковое соотношение полярных смыслов, транслируемых ключевыми свойствами личности. Данный баланс - промежуточное положение между двумя способами образования смыслов, в протекании которых возможен равновероятный выбор (бифуркация).

Третья, преадаnтивная (лат. «ргае» - впереди, перед) стратегия смыслообразования начинается с нейтральной точки и открывает направление парадоксального подхода к взаимодействию в ситуациях. Как неравновесный третий аттрактор, это показывает направление неочевидного, но возможного развития личности с несколькими альтернативами. Преадаптивная стратегия показывает наличие такого положительного ключевого личностного свойства, которое помогает выполнять дополнительные функции, либо успешно взаимодействовать в будущем как в непредвиденных условиях новых ситуаций. Аккомодационный характер данной стратегии означает проявление личной активности для вариабельного приспособления поведенческих схем, что означает их предвосхищающую природу. Происходящая при этом перестройка смысловой сферы личности свидетельствует о ее самосовершенствовании как духовном росте.

Рассмотренные выше две адаптивные стратегии исходят из предопределенности целей и заданной внешней средой нормы ситуативной активности отражают наличие жесткой причинно-следственной связи между жизненными отношениями человека и реализующим их поведением. Для преодоления таких ограничений адаптивности целесообразно говорить о надситуативной активности субъекта - преадаптивности [37]. В таком состоянии действующие причинные связи могут становиться менее строгими условиями жизни - появляется вариативность развития. В процессе совершенствования личности жесткие причины ее жизнедеятельности, порождающие необходимость реализации однозначных следствий, замещаются на предпосылки, формирующие возможность осуществления своего развития. Преадаптивность является одним из главных атрибутов творческого потенциала, материалом для раскрытия 
которого, согласно Книге Перемен, является взаимодействие с хаосом. Встав на путь творческого действия, человеку требуется проявлять стойкость в его осуществлении, тогда накопленной полноты сил, как преадаптивных свойств, хватит для благотворной деятельности и достижения гармонии [31].

Преадаптивная личность имеет не внешний, а внутренний локус контроля своей жизни - интернальность, т. е. ответственность за свою жизнь принимает на себя, объясняя происходящее особенностями своего характера, своим поведением, способностями, умением строить отношения [33]. В ситуациях фрустрации у такого человека преобладает необходимо-упорствующий тип реагирования, как фиксация на разрешении ситуации разными способами: собственными силами, с помощью других людей или по естественному ходу событий, что представляется конструктивным [36]. Преадаптивные свойства для личности в ситуациях, протекаемых в настоящем, на первый взгляд кажутся избыточными и лишними. Однако в будущих ситуациях с новыми условиями именно преадаптивные свойства личности позволяют преодолевать кризисные состояния как внешнего, так и внутреннего порядка. Наличие толерантности к неопределенности отражает у человека важный атрибут Я-концепции - самосовершенствование его живой системы, как самонаводящейся на поиск и исполнение высшего смысла своей жизни. При таком осуществлении проявляется самотрансценденция как истинное духовное преображение человека, означающее выход за границы своего фактического феноменального бытия как «выход за свои пределы», к надличностным целям бытия, к высшему смыслу своей жизни и исполнению его как верховного промысла [38].

Д. А. Леонтьев в исследовании поведения человека предлагает дополнительно к традиционной психологии с акцентом на необходимость и детерминированность (то, чего не может не быть) выделять «вторую» психологию, акцентирующуюся на возможностях и самодетерминации, которые не порождаются строгими причинно-следственными связями, но могут быть. При этом траектория человека, кроме субчеловеческого, малозатратного существования может иметь собственно человеческий - автономный уровень развития для ориентации поведения в пространстве возможного, что является парадоксальным по отношению к обыденной детерминированности жизни [20]. Нелинейный переход от необходимости к вееру возможностейпарадоксальный поступок синергетической природы, который не оправдан с позиции низших биологических регуляторов, но является уникальным и осмысленным с позиции высших ценностей.

Так как суть самотрансценденции составляет поиск смысла жизни как высшего предназначения и его осуществление, то применение парадоксальной логики в обычных ситуациях возможно, когда человек знает о высших путях. Поиск предназначения - очень большой риск, самая трудная работа, 
которая может и не привести к автоматическому успеху [39]. А. Маслоу в одном из поздних интервью сказал о том, что эмпирически не подтвердился его тезис о том, что удовлетворение базовых потребностей человека является однозначной причиной, неизбежно и безоговорочно порождающей переход его личности к самоактуализации. Им указано, что после выхода на уровень, когда базовые потребности не являются критическими для жизнедеятельности, одна часть людей продолжает двигаться в сторону самоактуализации, а другая часть останавливается [40]. Пока человек в поиске себя, он перебирает свои способности и не может ощутить свою состоятельность и зрелость - когда человек идет в новое, он слабо защищен в своем творчестве - уязвим в сравнении с теми, кто остается в зоне комфорта.

Нами предлагается следующее определение: преадаптивная смыслообразующая стратегия - это ориентированный на осознание мотивов и порождение актуальных целей способ формирования каузальных образов, направленный на формирование перспективных личностных смыслов и их своевременную трансформацию для осуществления возможности духовного роста под влиянием внутренних и внешних обстоятельств, оцениваемых как преодолимые условия жизненных ситуаций при самодетерминации индивидом своей деятельности.

\section{Заключение}

Три предлагаемые стратегии, задающие направленность и качественное содержание образуемых смыслов, реализуют принципиально разные подходы к взаимодействию в ситуациях. В гипоадаптивной и гиперадаптивной стратегиях происходит включение новой информации в имеющиеся схемы и последующее схематичное действие с новыми объектами на основе уже сложившихся умений и навыков. В преадаптивной стратегии происходит вариабельное приспособление схем поведения к новым ситуациям, требующим определенной активности, в том числе надситуативной, что означает ее предвосхищающий характер.

Представленный триалектический подход к изучению смыслообразующих стратегий может быть использован для выявления троичной организации комплекса свойств личности. В дальнейших исследованиях планируется эмпирическое изучение особенностей предложенных смыслообразующих стратегий, для которых будут разработаны семантические троичные шкалы. Тестирование с их применением будет проводиться совместно с комплексом апробированных методик на выявление особенностей смысловой регуляции. Применение такого троичного инструмента позволяет выявлять триады ключевых личностных свойств личности и их корреляцию с другими критериями развития смысловой сферы. На этой основе возможно построение 


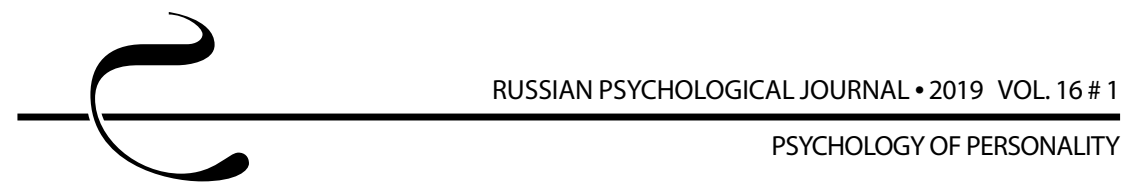

личностного профиля, выступающего мультифакторной моделью возможных состояний ценностно-смысловой сферы переживающего субъекта. В плане моделирования поведения, как одной из главных задач психологии, такой личностный профиль показывает направленность и качественные особенности смысловой регуляции - отражает актуально действующую стратегию образования смыслов как полимодальных каузальных образов.

\section{Благодарности}

Исследование выполнено в рамках реализации внутреннего гранта ЮФУ № ВнГр-07/2017-01 «Разработка технологий инициации смыслообразования как компонента современных коммуникативных систем с целью обеспечения информационной безопасности сети Интернет».

\section{Acknowledgments}

The financial support of the Southern Federal University (project no. 07/2017-01, "Developing the technologies of meaning-building initiation as a component of modern communication systems with the view of ensuring information security of the Internet") is gratefully acknowledged.

\section{Литература}

1. Годунов М. В. Психологические особенности актуализации полярных оценок в смысловом пространстве у лиц с различными стратегиями смыслообразования: дисс. ... канд. психол. наук. Ростов-на-Дону, 2017. 152 с.

2. Леонтьев Д. А. Очерк психологии личности. 2-е изд. М.: Смысл, 1997. 64 с.

3. Выготский Л. С. Мышление и речь. М.: Национальное образование, 2016. 368 C.

4. Мясищев В. Н. Структура личности и отношение человека к действительности // Психология личности. Хрестоматия. 9-е изд. Т. 2. Отечественная психология / под ред. Д. Я. Райгородского. Самара: Бахрах-М, 2013. C. 221-224.

5. Леонтьев А. Н. Деятельность и сознание // Общая теория смысла, психологические концепции смыслообразования, смыслодидактика. Хрестоматия / сост. И. В. Абакумова, П. Н. Ермаков, И. А. Рудакова. М.: КРЕДО, 2014. С. 268-284.

6. Аллахвердов В. М. Сознание как парадокс (Экспериментальная психологика, Т. 1). СПб: «Издательство ДНК», 2000. 528 с.

7. Карпов А. В. Метасистемный подход к проблеме сознания // Мир психологии. 2016. № 2 (86). С. 15-31.

8. Агафонов А. Ю. Когнитивная психомеханика сознания, или как сознание неосознанно принимает решение об осознании. Самара: Универс Групп, 2006. 348 с. 
9. Петренко В.Ф. Многомерное сознание: психосемантическая парадигма. 2-е изд., доп. М.: Эксмо, 2013. 448 с.

10. Allport G. W. Becoming: Basic Considerations for a Psychology of Personality. New Haven: Yale University Press, 1956. 106 p.

11. Нуркова В. В. Общая психология:учебник для академического бакалавриата / В. В. Нуркова, Н. Б. Березанская. 3-е изд., перераб. М.: Юрайт, 2015.604 с.

12. Vasilyuk F. E. Coexperiencing Psychotherapy as a Psychotechnical System // Journal of Russian \& East European Psychology. 2015. Vol. 52, Issue 1. P. 1-58. DOI: $10.1080 / 10610405.2015 .1064721$

13. Краткий философский словарь / А. П. Алексеев, Г. Г. Васильев [и др.]. Под ред. А. П. Алексеева. 2-е изд., перераб. и доп. М.: РГ-Пресс, 2013. 496 с.

14. Кант И. Критика чистого разума / пер. с нем. Н. Лосского. М.: АСТ, 2017. $784 \mathrm{c}$

15. Гуревич А. Я. Исторический синтез и Школа «Анналов». М.: Индрик, 1993. $327 \mathrm{c}$.

16. Лощилов В. И. Информационно-волновая медицина и биология. М.: Аллегро-пресс, 1998. 256 с.

17. Абакумова И. В. Обучение как двуединый процесс и его движущие силы в смысловой интерпретации // Общая теория смысла, психологические концепции смыслообразования, смыслодидактика. Хрестоматия / сост. И. В. Абакумова, П. Н. Ермаков, И. А. Рудакова. М.: КРЕДО, 2014. С. 10-18.

18. Чаттерджи С., Датта Д. Индийская философия. М: Академический проект, 2017. 365 с.

19. Леонтьев Д. А. Психология смысла: природа, строение и динамика смысловой реальности. 3-е изд., доп. М.: Смысл, 2007. 511 с.

20. Леонтьев Д. А. Новые ориентиры в понимании психологии личности: от необходимого к возможному // Вопросы психологии. 2011. № 1. С. 3-27.

21. Почепиов Г. Г. Стратегия. М.: Рефл-бук; К.: Ваклер, 2005. 384 с.

22. Достоевский Ф. М. Братья Карамазовы. М.: Эксмо, 2016. 926 с.

23. Семёнов В. Е. Российская идентичность и патриотизм в полиментальном обществе // Институт психологии Российской академии наук. Социальная и экономическая психология. 2017. Т. 2, № 2. С. 116-143.

24. Аристотель. Этика. М.: Эксмо-Пресс, 2018. 320 с.

25. Платон. Диалоги. М.: Эксмо, 2016. 768 с.

26. Proclos. Commentary on Plato's Parmenides / translated by G. Morrow \& J. DilIon; with introduction and notes by J. Dillon. Princeton, NJ, USA: Princeton University Press, 2017. $664 \mathrm{p}$.

27. Гегель Г. В. Ф. Введение в философию. Философская пропедевтика (Серия: Из наследия мировой философской мысли. История философии) / пер. С. Ф. Васильевой. М.: Либроком, 2018. 264 с. 


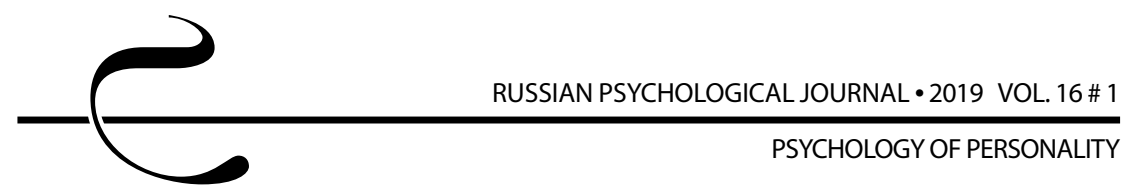

28. Kelly G. The psychology of personal constructs (Vols. 1 and 2). N.Y:: Norton, $1955.495 \mathrm{p}$.

29. Мандрикова Е. Ю. Виды личностного выбора и их индивидуально-психологические предпосылки:дисс. ... канд. психол. наук. М.: Изд-во МГУ, 2006. $195 \mathrm{c}$.

30. Остапенко А. А. Моделирование многомерной педагогической реальности: теория и технологии. М.: Народное образование, 2005. 384 с.

31. Щуцкий Ю. К. Китайская классическая «Книга Перемен». М.: Восточная литература, 2003.606 с.

32. Жесткова Н. А. Методологические подходы к исследованию социальной зрелости и социального инфантилизма личности // Вестник Пермского университета. Философия. Социология. Психология. 2013. № 2 (14). C. 128-136.

33. Ощепкова Г. И. Проявление экстернальности и интернальности при зависимом поведении // Филология и культура. 2015. № 3 (41). С. 333-337.

34. Вишневецкий К. В. Классификация виктимности // Теория и практика общественного развития. 2014. № 2. С. 417-418.

35. Ивановская О. В. Трансценденция против трансгрессии // Научные проблемы гуманитарных исследований. 2010. № 1. С. 256-268.

36. Rosenzweig S. The picture-association method and its application in a study of reaction to frustration // Journal of Personality. 1945. Vol. 14, № 1. P. 3-23.

37. Петровский В. А. Личность как субъект активности // Психология личности. Хрестоматия. 9-е изд. Т. 2. Отечественная психология / под ред. Д. Я. Райгородского. Самара: Бахрах-М, 2013. С. 463-484.

38. FrankI V. The Doctor and the Soul. N.Y.: Vintage Books, 1973. 352 p.

39. Adler A. Psychotherapie und Erziehung: Ausgewählte Aufsätze. Band I: 1919-1929/ Hg. von H. L. Ansbacher, R. F. Antoch. Frankfurt am Main: Fischer Taschenbuch Verlag, 1982. $267 \mathrm{~s}$.

40. Frick W. Remembering Maslow: Reflections on a 1968 Interview // Journal of Humanistic Psychology. 2000. Vol. 40, Issue 2. P. 128-147. DOI: $\underline{10.1177 / 0022167800402003}$

\section{References}

1. Godunov M.V. Psikhologicheskie osobennosti aktualizatsii polyarnykh otsenok $v$ smyslovom prostranstve u lits s razlichnymi strategiyami smysloobrazovaniya [Psychological features of actualization of polar estimates in meaning space in individuals with different strategies of meaning-building]. Diss. Cand. Sci. (Psych.). Rostov-on-Don, 2017. 152 p.

2. Leont'ev D. A. Ocherk psikhologii lichnosti [Essay on the psychology of personality]. Moscow, Smysl Publ., 1997. 64 p. 
3. Vygotskii L. S. Myshlenie irech' [Thinking and speech]. Moscow, Natsional'noe obrazovanie Publ., 2016. 368 p.

4. Myasishchev V. N. The structure of personality and individuals' attitudes towards reality. In: D. Ya. Raigorodskii (ed.) Psikhologiya lichnosti. Khrestomatiya. 9-eizd. T. 2. Otechestvennaya psikhologiya [Psychology of personality: V. 2: Soviet psychology]. Samara, Bakhrakh-M Publ., 2013, pp. 221-224.

5. Leont'ev A. N. Activity and consciousness. In: Abakumova I. V., Ermakov P. N., Rudakova I. A. Obshchaya teoriya smysla, psikhologicheskie kontseptsii smysloobrazovaniya, smyslodidaktika. Khrestomatiya [General theory of meaning, psychological concepts of meaning-building, meaning didactics]. Moscow, Kredo Publ., 2014, pp. 268-284.

6. Allakhverdov V. M. Soznanie kak paradox: Eksperimental'naya psikhologika: T. 1 [Consciousness as a paradox: Experimental psychologic: V. 1]. St. Petersburg, Izdatel'stvo DNK, 2000. 528 p.

7. Karpov A. V. Metasystemic approach to the problem of consciousness. Mir psikhologii - World of Psychology, 2016, no. 2 (86), pp. 15-31 (in Russian).

8. Agafonov A. Yu. Kognitivnaya psikhomekhanika soznaniya, ili kak soznanie neosoznanno prinimaet reshenie ob osoznanii [Cognitive psychomechanic of consciousness, or how consciousness unconsciously makes a decision about perception]. Samara, Univers Grupp Publ., 2006. 348 p.

9. Petrenko V. F. Mnogomernoe soznanie: psikhosemanticheskaya paradigma [Multidimensional consciousness: A psychosemantic paradigm]. Moscow, Eksmo Publ., 2013. 448 p.

10. Allport G. W. Becoming: Basic considerations for a psychology of personality. New Haven, Yale University Press, 1956. 106 p.

11. Nurkova V. V. Obshchaya psikhologiya: uchebnik dlya akademicheskogo bakalavriata [General psychology: A textbook for academic baccalaureate]. Moscow, Yurait Publ., 2015. 604 p.

12. Vasilyuk F. E. Coexperiencing psychotherapy as a psychotechnical system. Journal of Russian \& East European Psychology, 2015, V. 52, Issue 1, pp. 1-58. DOI: $10.1080 / 10610405.2015 .1064721$

13. Alekseev A. P., Vasil'ev G. G. Kratkii filosofskii slovar' [Desk dictionary of philosophy]. Moscow, RG-Press Publ., 2013. 496 p.

14. Kant I. Kritika chistogo razuma [Critique of pure reason]. Moscow, AST Publ., 2017. $784 \mathrm{p}$.

15. Gurevich A. Ya. Istoricheskii sintez i Shkola "Annalov" [Historical synthesis and the Annales school]. Moscow, Indrik Publ., 1993. 327 p.

16. Loshchilov V. I. Informatsionno-volnovaya meditsina i biologiya [Information-wave medicine and biology]. Moscow, Allegro-press Publ., 1998. $256 \mathrm{p}$. 
17. Abakumova I.V. Teaching as a dual process and its driving forces in a meaning interpretation. In: Abakumova I. V., Ermakov P. N., Rudakova I. A. Obshchaya teoriya smysla, psikhologicheskie kontseptsii smysloobrazovaniya, smyslodidaktika. Khrestomatiya [General theory of meaning, psychological concepts of meaning-building, meaning didactics]. Moscow, Kredo Publ., 2014, pp. 10-18.

18. Chatterjee S., Datta D. Indiiskaya filosofiya [Indian philosophy]. Moscow, Akademicheskii proekt Publ., 2017. 365 p.

19. Leont'ev D. A. Psikhologiya smysla: priroda, stroenie i dinamika smyslovoi real'nosti [Psychology of meaning: Nature, structure, and dynamics of meaning reality]. Moscow, Smysl Publ., 2007. 511 p.

20. Leont'ev D. A. New benchmarks in the understanding of personality psychology: from the necessary to the possible. Voprosy Psikhologii, 2011, no. 1, pp. 3-27 (in Russian).

21. Pocheptsov G. G. Strategiya [Strategy]. Moscow, Refl-Buk Publ., 2005. 384 p.

22. Dostoevskii F. M. Brat'ya Karamazovy [Brothers Karamazov]. Moscow, Eksmo Publ., 2016. 926 p.

23. Semenov V. E. Russian identity and patriotism in a polymental society. Institut psikhologii Rossiiskoi akademii nauk. Sotsial'naya i ekonomicheskaya psikhologiya - Institute of Psychology of the Russian Academy of Sciences: Social and Economic Psychology, 2017, V. 2, no. 2, pp. 116-143 (in Russian).

24. Aristotle. Ethics. Moscow, Eksmo-Press Publ., 2018. 320 p. (in Russian).

25. Plato. Dialogues. Moscow, Eksmo Publ., 2016. 768 p. (in Russian).

26. Proclos. Commentary on Plato's Parmenides. Translated by G. Morrow \& J. DilIon; with introduction and notes by J. Dillon. Princeton, NJ, USA, Princeton University Press, 2017.664 p.

27. Hegel G. W. F. Introduction to philosophy: Philosophical propaedeutics. Moscow, Librokom Publ., 2018. 264 p. (in Russian).

28. Kelly G. The psychology of personal constructs (Vols. 1 and 2). N.Y., Norton Publ., 1955. 495 p.

29. Mandrikova E. Yu. Vidy lichnostnogo vybora i ikh individual'no-psikhologicheskie predposylki [Types of personal choice and their individual-psychological preconditions]. Diss. Cand. Sci. (Psych.). Moscow, Moscow State University Publ., 2006. $195 \mathrm{p}$.

30. Ostapenko A. A. Modelirovanie mnogomernoi pedagogicheskoi real'nosti: teoriya itekhnologii [Modeling multidimensional educational reality: Theory and technology]. Moscow, Narodnoe obrazovanie Publ., 2005. 384 p.

31. Shchutskii Yu. K. Kitaiskaya klassicheskaya "Kniga Peremen" [The classical Chinese Book of Changes]. Moscow, Vostochnaya literatura Publ., 2003. $606 \mathrm{p}$. 
32. Zhestkova N. A. Methodological approaches to studying social maturity and social infantilism of personality. Vestnik Permskogo universiteta. Filosofiya. Sotsiologiya. Psikhologiya - Bulletin of Perm University. Philosophy. Sociology. Psychology, 2013, no. 2 (14), pp. 128-136 (in Russian).

33. Oshchepkova G. I. Manifestation of externality and internality with dependent behavior. Filologiya i kul'tura - Philology and Culture, 2015, no. 3 (41), pp. 333-337 (in Russian).

34. Vishnevetskii K. V. Classification of victimization. Teoriya i praktika obshchestvennogo razvitiya - Theory and Practice of Social Development, 2014, no. 2, pp. 417-418 (in Russian).

35. Ivanovskaya O.V. Transcendence against transgression. Nauchnye problemy gumanitarnykh issledovanii - Scientific Problems of Humanitarian Studies, 2010, no. 1, pp. 256-268 (in Russian).

36. Rosenzweig S. The picture-association method and its application in a study of reaction to frustration. Journal of Personality, 1945, V. 14, no. 1, pp. 3-23.

37. Petrovskii V. A. Personality as a subject of activity. In: D. Ya. Raigorodskii (ed.) Psikhologiya lichnosti. Khrestomatiya. 9-e izd. T. 2. Otechestvennaya psikhologiya [Psychology of personality: V. 2: Soviet psychology]. Samara, Bakhrakh-M Publ., 2013, pp. 463-484.

38. Frankl V. The doctor and the soul. N.Y., Vintage Books, 1973. 352 p.

39. Adler A. Psychotherapie und Erziehung: Ausgewählte Aufsätze. Band I: 1919-1929. Frankfurt am Main, Fischer Taschenbuch Verlag, 1982. 267 s.

40. Frick W. Remembering Maslow: Reflections on a 1968 Interview. Journal of Humanistic Psychology, 2000, V. 40, Issue 2, pp. 128-147. DOI: 10.1177/0022167800402003 